\title{
AVALIAÇÃO DE IMPLANTAÇÃO DE SISTEMA DE REÚSO DE ÁGUAS CINZAS PARA FINS NÃO POTÁVEIS EM UMA EDIFICAÇÃO DE ENSINO
}

\author{
DEPLOYMENT ASSESSMENT OF THE GREYWATER OF A SCHOOL BUILDING VIEWING \\ REUSE TO NON-POTABLE PURPOSES
}

\author{
Akemi Yoshizane Masalaa, Lineker Max Goulart Coelhoa \\ ${ }^{a}$ Centro Federal de Educação Tecnológica de Minas Gerais - Cefet-MG \\ a.yoshizane@gmail.com,lineker.goulart@gmail.com
}

Submissão: 21 de maio de 2020 Aceitação: 1 de julho de 2021

\section{Resumo}

A água é a substância mais abundante na superfície da Terra. Porém, analisando o cenário atual, percebese um crescimento acelerado da população, juntamente com o desenvolvimento das cidades e indústrias, provocando um aumento da demanda de recursos hídricos. Tendo em vista esta realidade, o reúso de águas cinzas é uma das alterativas sustentáveis que contribui para o uso racional da água. O objetivo deste trabalho foi realizar uma avaliação qualitativa e quantitativa das águas cinzas geradas nos lavatórios das instalações sanitárias do prédio 20 do Centro Federal de Educação Tecnológica de Minas Gerais (CefetMG), com a intenção de elaborar um sistema de reúso. A metodologia utilizada consistiu em monitoramentos diários e ensaios de caracterização das amostras, como também uma análise econômica para implantação desse tipo de sistema. Os resultados obtidos nesta pesquisa mostraram que as águas cinzas apresentam características que possibilitam o seu reúso, ainda que o volume demandado seja muito maior do que o gerado; e que investimento necessário para implantação do sistema descrito seria recuperado em 38 meses.

Palavras-chave: Águas cinzas. Análise de água. Reúso de água.

\section{Abstract}

Water is the most abundant element on the Earth surface. However, analyzing the current scenario in the global level, there is an accelerated population growth along with the development of the cities and industries, causing an increase in the demand for water resources. Because of this, the reuse of greywater is one of the sustainable alternatives and contributes to the rational use of water. This work aims to elaborate a system of reuse of the greywater of the bathroom sinks of building 20 of Cefet-MG. Daily monitoring and characterization tests were carried out in this research, and an economic analysis to implement the system was performed. The results showed that the greywater have characteristics that allow their reuse, however, the volume demanded is much larger than the one generated. The investment made would be recovered in 38 months.

Keywords: Greywater. Water analysis. Water reuse.

\section{INTRODUÇÃO}

A água é um recurso natural de extrema importância para os seres vivos. Todavia, trata-se de um bem esgotável. Dado o cenário atual de crescimento populacional acelerado, o desenvolvimento das cidades, o progresso das indústrias e, consequentemente, o aumento da poluição, o fornecimento hídrico tem se tornado cada vez mais difícil. Tais fatores provocaram um aumento da demanda de água e têm comprometido o abastecimento devido ao lançamento de esgoto nos mananciais. Segundo o Relatório Mundial da Organização das Nações 
Unidas para a Educação, a Ciência e a CulturaUnesco, sobre o desenvolvimento dos recursos hídricos (UNESCO, 2015), a desproporção entre a demanda e a oferta causará um déficit de água em escala global.

Diante desse contexto, com intuito de amenizar o problema da escassez hídrica, diversos países iniciaram pesquisas para utilização de fontes alternativas de água, como o aproveitamento de águas pluviais e o reúso de águas cinzas, sendo este o foco desta pesquisa.

As águas cinzas são definidas como águas residuais oriundas de chuveiros, banheiras, lavatórios, tanques e máquinas de lavar, que possuem uma baixa concentração de poluentes. As águas das bacias sanitárias e pias de cozinha não são classificadas neste grupo, já que apresentam elevada carga orgânica.

Para o reúso da água cinza, é necessário satisfazer exigências mínimas de qualidade, conforme recomendado na NBR 13.969/1997 (ABNT, 1997). A fim de atingir esse objetivo, são realizados ensaios de controle e, posteriormente, tratamentos adequados.

As instituições de ensino são locais com grande potencial para o reúso de águas, dado o volume significativo de consumo diário. As águas coletadas dos lavatórios, após tratamento adequado, podem ser utilizadas em descargas sanitárias e lavagem de pisos, por exemplo (BRAGA; RIBEIRO JÚNIOR, 2016).

Com essas considerações, o presente trabalho tem como objetivo realizar uma avaliação qualitativa e quantitativa das águas cinzas geradas no prédio 20 da instituição de ensino técnico e superior Centro Federal de Educação Tecnológica de Minas Gerais (Cefet-MG) Campus 2 e analisar a viabilidade da implantação de um sistema de seu reúso.

\section{FUNDAMENTAÇÃO TEÓRICA}

\section{A água no planeta}

Aproximadamente $70 \%$ da superfície da Terra é composta por água. De toda essa quantidade, $97 \%$ estão concentrados nas águas marítimas e os $3 \%$ restantes referem-se à porcentagem de água doce existente, distribuída em geleiras e calotas polares $(2,2 \%)$ e em água doce na forma líquida $(0,8 \%)$. Ou seja, apenas uma pequena parcela está disponível para o consumo humano (BARROS; AMIN, 2007).
O Brasil detém cerca de $13 \%$ de toda água superficial distribuída no planeta. No entanto, a sua distribuição é desigual. Aproximadamente $70 \%$ desse volume encontra-se na Bacia Amazônica, na região que apresenta menor densidade populacional do país. E de maneira oposta, na Região Metropolitana de São Paulo (RMSP), onde apenas $0,06 \%$ da água doce do Brasil está disponível, concentra-se cerca de 10\% da população nacional. Isso mostra a falta de uniformidade na distribuição do recurso hídrico no país (MONTEIRO, 2009).

Em uma matéria publicada pela revista Veja, em 12 de outubro de 2005, Lima (2005) informa que essa má distribuição da água não se limita ao território brasileiro, ocorrendo também em regiões como o Oriente Médio e a África, que muitas vezes têm problemas e até conflitos devido à escassez deste bem. Além disso, as áreas mais ricas dessas regiões, às vezes, apresentam distâncias consideráveis entre as fontes de água e os consumidores.

\section{Reúso de águas cinzas}

O desenvolvimento acelerado e insustentável da sociedade e das indústrias promove um desequilíbrio entre a demanda e oferta de água em escala global. Estima-se que, em 2050, essa demanda aumente em 55\% (UNESCO, 2015). Tendo em vista essa realidade, o reúso de águas cinzas é uma das alterativas sustentáveis e que contribui para o uso racional da água, proporcionando a conservação dos recursos hídricos para as futuras gerações (PAULA; FERNANDES, 2018).

As águas cinzas são as águas utilizadas em residências e edificações, excluindo-se as águas provenientes dos vasos sanitários. Estas, por sua vez, são denominadas de águas negras. Consideram-se águas cinzas, então, apenas as águas residuais de chuveiros, banheiras, lavatórios, tanques, pias de cozinha, máquinas de lavar roupas e louças (CHRISPIM, 2014). Para as águas cinzas serem utilizadas, é necessário aplicar processos físicos (recursos de natureza física como filtração, decantação, peneiramento e floculação), biológicos (atividades biológicas ou bioquímicas como lodos aditivados, filtros biológicos e reatores anaeróbios) e até mesmo químicos (aplicação de produtos químicos ou reações químicas como a desinfecção, correção de $\mathrm{pH}$, eletro-diálise e oxidação). Isso porque, em algumas situações, os dois primeiros processos 
citados podem não ser suficientes para que se atinjam os valores ótimos de qualidade exigidos (PAULA; FERNANDES, 2018).

Os edifícios mais recentes que contam com sistemas de reúso de águas possuem uma estação de tratamento de águas cinzas (ETAC), dimensionadas conforme volume de efluente gerado. O tratamento na ETAC inicia-se com a coleta das águas cinzas por meio de tubulações de esgoto independentes, seguido do seu transporte até o decantador primário, onde ocorre a remoção dos sólidos decantados. A próxima etapa consiste em deixar a água em um tanque de tratamento biológico, em que partículas orgânicas são digeridas por bactérias desenvolvidas pela própria água cinza. Nesse tanque, há rotores para auxiliar a oxigenação da água e evitar o mau cheiro. A quarta etapa consiste na permanência da água em um decantador secundário para a remoção das partículas sedimentáveis remanescentes. Após essa etapa, a água segue para o tanque de acúmulo, por onde passa por um filtro composto de areia com diferentes granulometrias e carvão ativado, além de receber adição de cloro para sua desinfecção, e chega, por fim, ao reservatório de águas cinzas, pronto para uso não potável (PAULA et al., 2018).

\section{Parâmetros físicos, químicos e biológicos}

O manual de controle da qualidade da água elaborado pela Fundação Nacional da Saúde (FUNASA, 2014) classifica os parâmetros da água em:

- Parâmetros físicos: temperatura, sabor e odor, cor, turbidez, sólidos, condutividade elétrica.

- Parâmetros químicos: pH, alcalinidade e acidez, dureza, cloretos, série nitrogenada, fósforo, fluoretos, ferro e manganês, oxigênio dissolvido, DBO e DQO, micropoluentes.

- Parâmetros biológicos: micro-organismos de importância sanitária, indicadores de qualidade biológica, comunidades hidrobiológicas, cianobactérias.

\section{NBR 13969/1997}

Em 1997, a Associação Brasileira de Normas Técnicas criou a NBR 13969:1997 (ABNT, 1997), que aborda em seu item 5.6 a possibilidade do reúso de águas cinzas de esgotos de origem doméstica, ou com características similares, após o seu tratamento adequado e em usos nos quais a potabilidade não é exigida e em que haja segurança em termos sanitários, tais como: a irrigação de jardins e campos agrícolas, lavagem de pisos e veículos automotivos, descarga de vasos sanitários, manutenção paisagística dos lagos e canais com água, entre outros. A referida norma define também as classes e os parâmetros para os esgotos, conforme o reúso previsto (MAY, 2009).

As classes definidas foram:

- CLASSE 1: As águas dessa classe são destinadas aos usos que tenham contato direto com o ser humano e possível aspiração de aerossóis pelo operador;

- CLASSE 2: lavagens de pisos, calçadas e irrigação de jardins, manutenção de lagos e canais para fins paisagísticos, exceto chafarizes;

- CLASSE 3: descargas de vasos sanitários;

- CLASSE 4: reúso nos pomares, cereais, forragens, pastagens para gados e outros cultivos através de escoamento superficial ou por sistema de irrigação pontual. As aplicações devem ser interrompidas pelo menos 10 dias antes da colheita.

\section{Parâmetros econômicos}

Para qualquer investimento pretendido, é necessário realizar uma avaliação econômica para se averiguar a sua viabilidade. Para tal, seis ferramentas podem ser utilizadas: payback simples, payback descontado, VPL (Valor Presente Líquido), TIR (Taxa Interna de Retorno), TIRM (Taxa Interna de Retorno Modificada) e IL (Índice de Lucratividade) (BRIGHAN; GAPENSKI; ENRHARDT, 2001).

A pesquisa em questão utilizou-se do payback simples, do VPL e da TIR para analisar a viabilidade econômica do projeto proposto para reúso das águas cinzas do prédio 20. O payback simples refere-se ao período do tempo necessário para que as receitas líquidas de um investimento recuperem o custo de sua execução. No entanto, essa ferramenta não considera o custo de oportunidade do dinheiro ao longo desse tempo; é calculado conforme equação 1 (BRITO, 2012):

Payback simples

$=\left(\frac{\text { custo do investimento inicial }}{\text { fluxo de caixa no período }}\right)$

O VPL, diferentemente do payback simples, leva em consideração o valor do dinheiro no tempo, pois utiliza o valor presente dos fluxos de 
caixa futuros. Esta ferramenta auxilia na análise da rentabilidade do projeto (BRAGA, 2011). Valores de VPL maiores que zero indicam que 0 projeto em análise é viável, irá gerar mais caixa do que o previsto para suprir a liquidação das dívidas. De maneira análoga, VPL abaixo de zero implica um projeto inviável. Para $\mathrm{VPL}=0$, o projeto não terá lucro nem prejuízo (WESTON; BRIGHAN, 2004). O cálculo do indicador em questão se dá pela equação 2.

$$
\begin{aligned}
& V P L \\
& =\sum_{j=1}^{n} \frac{F c j}{(1+T M A)^{j}} \\
& - \text { Investimento inicial }
\end{aligned}
$$

Onde:

Fcj é o fluxo de caixa no período $j$;

jé o período de cada fluxo de caixa;

TMA é a taxa mínima de atratividade, ou seja, taxa mínima que um investimento deve remunerar para ser considerado economicamente viável.

A TIR é a taxa de desconto que um fluxo de caixa necessita para que seu VPL seja nulo. Dessa forma, o VPL das entradas de caixa deve ser igual ao VPL das saídas de caixa. O investimento é considerado viável quando TIR>TMA (CASAROTTO FILHO; KOPITTKE, 2010). A TIR é calculada conforme equação 3.

$$
\sum_{i=1}^{n} \frac{F c j}{(1+T I R)^{i}}-\text { Investimento inicial }=0
$$

Onde:

Fcj é o fluxo de caixa no período $j$;

i e o período de cada fluxo de caixa.

\section{METODOLOGIA}

\section{Área de estudo}

A área de estudo deste trabalho é o prédio 20 do campus 2 do Cefet-MG, localizado na avenida Amazonas, $\mathrm{n}^{\circ} 7675$, Bairro Gameleira, Belo Horizonte, Minas Gerais. O prédio 20 é um pavilhão de aulas inaugurado em 2017, constituído de 4 pavimentos: pavimento inferior (nível do estacionamento), pavimento térreo (nível do restaurante estudantil), primeiro e segundo pavimentos. Em cada andar há um banheiro feminino e um banheiro masculino. No pavimento térreo, também há banheiros na sala dos professores.

O campus 2 da instituição oferta serviços de ensino médio integrado ao ensino técnico, graduação, mestrado e doutorado, totalizando mais de 4.000 estudantes.

\section{Método de procedimento}

A pesquisa iniciou com a coleta das amostras de água cinza oriundas dos lavatórios do banheiro feminino do pavimento térreo. As amostras coletadas foram submetidas aos ensaios de caracterização, nos quais foram considerados apenas os parâmetros pH, condutividade elétrica e sólidos totais, devido à infraestrutura do laboratório. Em seguida, foi levantado o volume diário médio de água cinza gerado no banheiro feminino e os gastos mensais médios de água da instituição. Com os dados obtidos, foi elaborado um projeto preliminar de adaptação do prédio 20 para a realização da estimativa de custos e a análise de viabilidade econômica.

\section{Volume de água cinza gerado}

Para o levantamento do volume diário médio de águas cinzas que é gerado nos lavatórios do banheiro feminino, foram realizados monitoramentos ao longo dos períodos da manhã, tarde e noite durante 5 dias entre os meses de setembro/2019, outubro/2019 e novembro/2019.

O monitoramento considerou a quantidade de vezes que as torneiras foram utilizadas pelos alunos, professores e técnico-administrativos. Contudo, dadas as flutuações encontradas, serão adotados para esta pesquisa os valores diários médios. Os monitoramentos ocorreram nos seguintes horários: pela manhã, das $07 \mathrm{~h}$ às $12 \mathrm{~h}$ e $30 \mathrm{~min}$; à tarde, das $12 \mathrm{~h}$ e $30 \mathrm{~min}$ às $18 \mathrm{~h}$; e por fim o período das $18 \mathrm{~h}$ às $22 \mathrm{~h}$ e $30 \mathrm{~min}$ compreende os monitoramentos à noite.

\section{Consumo de água potável na instituição}

Para avaliar o consumo mensal médio de água potável no Cefet-MG campus 2, foram utilizadas as contas de água dos 12 meses anteriores ao início da pesquisa - setembro/2018 a setembro/2019. As contas foram emitidas pela 
Companhia de Saneamento de Minas Gerais (Copasa).

\section{Coleta das amostras}

As amostras de águas cinzas foram coletadas dos três lavatórios do banheiro feminino do pavimento térreo do prédio 20, nos dias 23/09/2019 (segunda-feira), 27/09/2019 (sextafeira), 03/10/2019 (quinta-feira), 24/10/2019 (quinta-feira) e 04/11/2019 (segunda-feira). As coletas foram realizadas diretamente do sifão, enquanto não havia pessoas utilizando os lavatórios. A figura 1 mostra os pontos de coleta.

Figura 1 - Os pontos de coleta

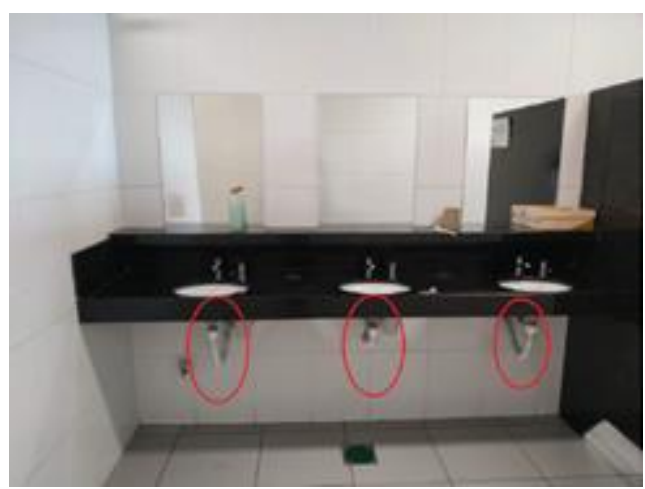

\section{Caracterização das amostras}

Para a caracterização das amostras, os ensaios foram realizados em duplicata no laboratório da pós-graduação, localizado no próprio campus do Cefet-MG. Os parâmetros de condutividade elétrica e $\mathrm{pH}$ foram realizados segundo o método potenciométrico. O parâmetro de sólidos totais, por sua vez, seguiu o método gravimétrico. Para todos os ensaios realizados, a referência adotada foi a ALPHA (2005). A figura 2 mostra os equipamentos utilizados em cada ensaio.

\section{Figura 2 - Equipamentos utilizados para caracterização das amostras}

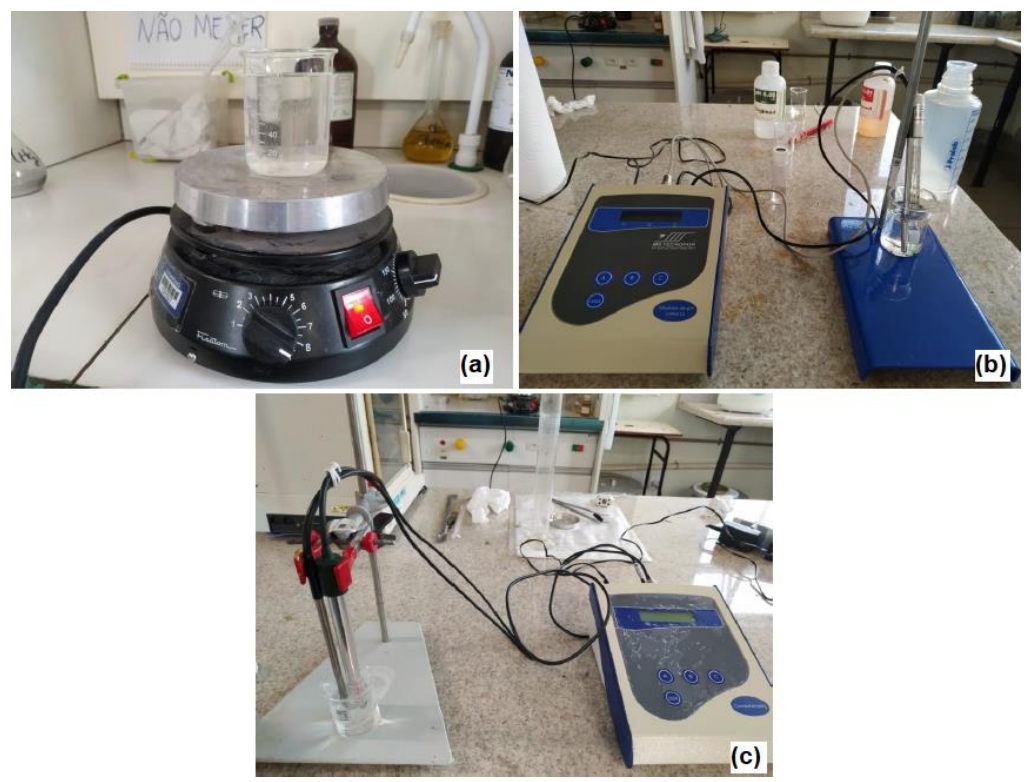

(a) equipamento utilizado no ensaio de sólidos totais; (b) equipamento utilizado para determinar o $\mathrm{pH}$; (c) equipamento para determinação da condutividade elétrica. 
Sistema de reúso de águas cinza

A proposta de adaptação do prédio 20 foi elaborada segundo as normas da ABNT NBR 5626:1998 e 8160:1999 (ABNT, 1998, 1999) para as instalações de água fria, esgoto, reservatórios inferior, superior e bomba. O projeto consiste na coleta das águas cinzas dos lavatórios dos banheiros e bebedouros para um reservatório inferior, onde esse esgoto será tratado com a adição de cloro, utilizando-se um clorador flutuante. A água armazenada nesse reservatório será bombeada para uma caixa d'água superior específica para este fim e, de lá, será direcionada para das descargas sanitárias e torneiras de limpeza. Ressalta-se a necessidade de sinalizar que a água das torneiras supracitadas não é indicada para finalidades potáveis. Na tubulação de saída do reservatório inferior, será instalado um filtro de água semelhante àqueles utilizados nos hidrômetros para reter partículas sólidas.

\section{Estimativa de custos}

Para a estimativa de custos da implantação, foram levantados os materiais de água fria e de esgoto necessários, como também os materiais para instalação dos reservatórios, reconstrução dos banheiros e a mão de obra necessária para a execução dos serviços. Essa estimativa baseouse na tabela dos preços não desonerados do Sistema Nacional de Pesquisa de Custos e Índices da Construção Civil (Sinapi) referente ao mês de setembro/2019. Para os materiais não encontrados no Sinapi, os preços foram obtidos por meio da média de três diferentes fornecedores.

Para a estimativa em questão, foi considerada a mão de obra paga por hora. A duração de cada uma das atividades necessárias foi determinada conforme o coeficiente estabelecido pelo Sinapi. Tal coeficiente refere-se ao índice de consumo: a incidência de cada insumo na execução de uma unidade de serviço, sendo expresso em unidade de tempo/unidade de trabalho.

\section{Análise econômica}

Para a análise econômica foram utilizadas as equações 1 , 2 e 3 apresentadas na fundamentação teórica.

\section{RESULTADOS OBTIDOS E DISCUSSÃO}

\section{Parâmetros analisados}

Os resultados obtidos nos ensaios realizados encontram-se relacionados nas tabelas 1,2 e 3 .

Os valores de $\mathrm{pH}$ obtidos encontram-se dentro da faixa estabelecida em norma $(6,5$ a 9,0) e próximos dos valores de $\mathrm{pH}$ da água potável. As amostras com valores médios mais elevados possivelmente possuem uma concentração maior de sabonetes e pastas de dente. A média global de 7,61 indica que, em relação a este parâmetro, os valores não demonstraram flutuações e sugere que os procedimentos foram realizados corretamente.

No que se refere à condutividade elétrica, com a exceção da coleta realizada no dia 23/09/2019, as amostras apresentaram condutividades na faixa de 150 a $180 \mu \mathrm{S} / \mathrm{cm}$, um bom indicativo, visto que a condutividade típica aproximada da água potável e da água mineral são, respectivamente, 50 e $200 \mu \mathrm{S} / \mathrm{cm}$ em temperatura ambiente. Mesmo considerando o resultado discrepante, obtém-se uma média global um pouco acima, mas ainda próxima da condutividade elétrica da água mineral - água com boa referência de qualidade. O outlier encontrado pode ser decorrente da falta de calibração do aparelho utilizado no ensaio. Levando-se em consideração que se trata da primeira coleta, os resultados encontrados podem ser também devido ao acúmulo de sais e sólidos no sifão ao longo do tempo, o que implica valores de concentração de sólidos totais maiores. A existência desse ponto fora da curva sugere a necessidade de realização de um número maior de coletas para se compreender a oscilação da água acerca deste parâmetro.

As águas de reúso enquadradas na classe 1 , segundo a NBR 13.969:1997 (ABNT, 1997) devem ter a concentração de sólidos totais de $200 \mathrm{mg} / \mathrm{L}$. As amostras coletadas apresentam uma concentração significativamente menor, não chegando nem a $1 \mathrm{mg} / \mathrm{L}$, o que viabiliza o reúso da água.

No cálculo da média global dos resultados das amostras, percebe-se uma flutuação nos valores das médias obtidos isoladamente. Isso sugere a necessidade da realização de mais ensaios para obtenção de números mais próximos da realidade. 
Tabela 1 - Resultados obtidos no ensaio de pH

\begin{tabular}{cccc}
\hline Data & Amostra 1 & Amostra 2 & Média \\
\hline $23 / 09 / 2019$ & 7,40 & 7,40 & 7,40 \\
$27 / 09 / 2019$ & 7,40 & 7,40 & 7,40 \\
$03 / 10 / 2019$ & 7,73 & 7,56 & 7,65 \\
$24 / 10 / 2019$ & 7,69 & 7,51 & 7,60 \\
$04 / 11 / 2019$ & 7,98 & 8,01 & 8,00 \\
& & & $\mathbf{7 , 6 1}$ \\
\hline
\end{tabular}

Tabela 2 - Resultados obtidos no ensaio de condutividade elétrica

\begin{tabular}{cccc}
\hline Data & $\begin{array}{c}\text { Amostra 1 } \\
(\boldsymbol{\mu S} / \mathbf{c m})\end{array}$ & $\begin{array}{c}\text { Amostra 2 } \\
(\boldsymbol{\mu S} / \mathbf{c m})\end{array}$ & $\begin{array}{c}\text { Média } \\
(\boldsymbol{\mu S} / \mathbf{c m})\end{array}$ \\
\hline $23 / 09 / 2019$ & 568,30 & 558,50 & 563,40 \\
$27 / 09 / 2019$ & 169,10 & 169,10 & 169,10 \\
$03 / 10 / 2019$ & 154,20 & 146,90 & 150,55 \\
$24 / 10 / 2019$ & 178,50 & 178,40 & 178,45 \\
$04 / 11 / 2019$ & 157,20 & 157,50 & 157,35 \\
& & & $\mathbf{2 4 3 , 7 7}$ \\
\hline
\end{tabular}

Tabela 3 - Resultados obtidos no ensaio de sólidos totais

\begin{tabular}{cccc}
\hline Data & $\begin{array}{c}\text { Amostra 1 } \\
(\mathbf{m g} / \mathbf{L})\end{array}$ & $\begin{array}{c}\text { Amostra 2 } \\
(\mathbf{m g} / \mathbf{L})\end{array}$ & $\begin{array}{c}\text { Média } \\
(\mathbf{m g} / \mathbf{L})\end{array}$ \\
\hline $23 / 09 / 2019$ & 0,68 & 1,36 & 1,02 \\
$27 / 09 / 2019$ & 0,32 & 0,57 & 0,45 \\
$03 / 10 / 2019$ & 0,15 & 0,11 & 0,13 \\
$24 / 10 / 2019$ & 0,58 & 0,37 & 0,48 \\
$04 / 11 / 2019$ & 0,88 & 0,81 & 0,85 \\
& & & $\mathbf{0 , 5 8}$ \\
\hline
\end{tabular}

Volume de água cinza gerado

Os valores obtidos no monitoramento encontram-se descritos na tabela 4.

Somando-se o número médio de acionamentos obtidos nos períodos da manhã, tarde e noite, tem-se, em média, 298 acionamentos diariamente.

A relação dos volumes de água consumidos em cada acionamento, expressos em $\mathrm{mL}$ para cada uma das torneiras, encontra-se na tabela 5 . Esses valores foram obtidos por meio da coleta da água no acionamento de cada torneira.

Conforme os valores expressos na tabela 5 , adotou-se para a pesquisa o volume médio de $905 \mathrm{~mL}$, ou seja, 0,905L por acionamento. Dessa forma, tem-se que o volume médio diário gerado é $269,69 \mathrm{~L}$.

\section{Consumo mensal médio de água potável}

O consumo mensal de água potável no Cefet-MG campus 2 juntamente com os custos monetários correspondentes a cada mês durante o período de setembro/2018 a setembro/2019 encontram-se listados na tabela 6.

Conforme as informações supracitadas, temse que o consumo médio mensal de água potável na instituição é de $1.317 \mathrm{~m}^{3}$ (1.317.000L) com custo médio mensal de $\mathrm{R} \$ 25.488,24$.

\section{Sistema de reúso de águas cinzas}

Reservatórios superior e inferior

O dimensionamento dos reservatórios foi realizado conforme a demanda de água nas bacias sanitárias do prédio 20 . Ghisi e Marinoski 
(2008) verificaram que em uma instituição de ensino a bacia sanitária é o aparelho responsável pela maior parcela de consumo de água e equivale a $65 \%$ do total.
Na tabela 7, estão listados os prédios que constituem o campus 2 do Cefet-MG e as suas respectivas quantidades de sanitários.

Tabela 4 - Valores obtidos no monitoramento do banheiro feminino

\begin{tabular}{cccc}
\hline Dia & $\begin{array}{c}\text { Manhã } \\
\text { (acionamentos } \\
\text { de torneira) }\end{array}$ & $\begin{array}{c}\text { Tarde } \\
\text { (acionamentos } \\
\text { de torneira) }\end{array}$ & $\begin{array}{c}\text { Noite } \\
\text { (acionamentos } \\
\text { de torneira) }\end{array}$ \\
Dia 1 & 110 & 102 & 52 \\
Dia 2 & 133 & 92 & 38 \\
Dia 3 & 148 & 107 & 61 \\
Dia 4 & 156 & 121 & 44 \\
Dia 5 & 123 & 143 & 58 \\
Média & $\mathbf{1 3 4}$ & $\mathbf{1 1 3}$ & $\mathbf{5 1}$ \\
\hline
\end{tabular}

Tabela 5 - Volume de água por acionamento

\begin{tabular}{cccc}
\hline Acionamento & $\begin{array}{c}\text { Torneira 1 } \\
(\mathbf{m L})\end{array}$ & $\begin{array}{c}\text { Torneira 2 } \\
(\mathbf{m L})\end{array}$ & $\begin{array}{c}\text { Torneira 3 } \\
(\mathbf{m L})\end{array}$ \\
\hline Acionamento 1 & 900 & 1000 & 800 \\
Acionamento 2 & 890 & 1000 & 830 \\
Acionamento 3 & 850 & 1000 & 850 \\
Acionamento 4 & 950 & 990 & 820 \\
Acionamento 5 & 910 & 950 & 830 \\
Média & $\mathbf{9 0 0}$ & $\mathbf{9 8 8}$ & $\mathbf{8 2 6}$ \\
\hline
\end{tabular}

Tabela 6 - Consumo mensal de água potável no campus 2

\begin{tabular}{cccccc}
\hline Data & $\begin{array}{c}\text { Consumo } \\
\left(\mathbf{m}^{\mathbf{3}}\right)\end{array}$ & Valor $(\mathbf{R} \$ \mathbf{)}$ & Data & $\begin{array}{c}\text { Consumo } \\
\left(\mathbf{m}^{\mathbf{3}}\right)\end{array}$ & Valor (R\$) \\
\hline Set/18 & 1405 & $\mathrm{R} \$ 26.728,04$ & $\mathrm{Abr} / 19$ & 1298 & $\mathrm{R} \$ 24.649,65$ \\
$\mathrm{Out} / 18$ & 1464 & $\mathrm{R} \$ 27.859,74$ & $\mathrm{Mai} / 19$ & 1319 & $\mathrm{R} \$ 25.060,24$ \\
$\mathrm{Nov} / 18$ & 1187 & $\mathrm{R} \$ 22.521,46$ & $\mathrm{Jun} / 19$ & 1236 & $\mathrm{R} \$ 25.021,16$ \\
$\mathrm{Dez} / 18$ & 1143 & $\mathrm{R} \$ 21.671,90$ & $\mathrm{Jul} / 19$ & 1231 & $\mathrm{R} \$ 23.466,46$ \\
$\mathrm{Jan} / 19$ & 580 & $\mathrm{R} \$ 10.795,14$ & $\mathrm{Ago} / 19$ & 1341 & $\mathrm{R} \$ 26.446,68$ \\
$\mathrm{Fev} / 19$ & 762 & $\mathrm{R} \$ 14.777,18$ & $\mathrm{Set} / 19$ & 1803 & $\mathrm{R} \$ 36.802,04$ \\
$\mathrm{Mar} / 19$ & 1037 & $\mathrm{R} \$ 20.059,24$ & & & \\
\hline
\end{tabular}

Tabela 7 - Prédios do campus $2 \mathrm{e}$ as respectivas quantidades de sanitários existentes

\begin{tabular}{lclc}
\hline \multicolumn{1}{c}{ Local } & Quantidade & \multicolumn{1}{c}{ Local } & Quantidade \\
\hline Prédio 1 & 16 & Prédio 14 & 2 \\
Prédio 2 & 8 & Prédio 17 & 8 \\
Prédio 4 & 7 & Prédio 18 & 8 \\
Prédio 6 & 10 & Prédio 19 & 41 \\
Prédio 7 & 18 & Prédio 20 & 38 \\
Prédio 12 & 22 & TOTAL & $\mathbf{1 7 8}$ \\
\hline
\end{tabular}


O volume mensal de água potável destinado às descargas sanitárias de todo o campus 2 é de 856.050L. Desse total, 182.752,25L são destinados ao prédio 20.

O volume diário médio de água cinza gerado em um banheiro é de 269,69L. Considerando 2 banheiros por pavimento, 4 pavimentos e 20 dias/mês, tem-se que o volume médio mensal de água cinza gerado no prédio 20 é de 43.150,40L.

São destinados $182.752,25$ litros de água potável para a alimentação dos 38 vasos sanitários localizados no prédio 20 . O volume de água cinza gerado, 43.150,40 litros, é significativamente menor do que o demandado. Para a elaboração de uma proposta mais funcional e economicamente viável, calculou-se quantos vasos sanitários esses $43.150,40$ litros de águas cinzas gerados conseguem alimentar. Esse volume é suficiente para abastecer apenas 9 vasos sanitários. O número de vasos sanitários alimentados corresponde a um pavimento. Assim sendo, a proposta do sistema de reúso de águas cinzas contemplará apenas o $2^{\circ}$ pavimento do pavilhão de aulas. Os demais pavimentos continuariam sendo alimentados pelo reservatório de água potável.

Segundo a NBR 5626/1998 (ABNT, 1998), o volume mínimo de água a ser reservado, deve corresponder ao necessário para abastecer a edificação durante o período de 24h. Dessa forma, o volume médio diário de 2.157,52L será distribuído da seguinte maneira:

$60 \%$ do total $(1.294,51 \mathrm{~L})$ será armazenado no reservatório inferior enterrado. Será adotado um tanque de polietileno com capacidade de $1.750 \mathrm{~L}$.

- 40\% do total $(863,01 \mathrm{~L})$ será armazenado no reservatório superior. Será adotada uma caixa d'água com capacidade de $1.000 \mathrm{~L}$.

Caso falte água cinza para abastecer as válvulas de descarga, o abastecimento do reservatório inferior será complementado pelo reservatório superior de água potável. As prumadas (a principal e a de recalque) irão descer rente ao perfil metálico da fachada do prédio 20. Para isso será utilizado um sistema elétrico de controle de nível, que libera a válvula de alimentação do reservatório superior com água potável quando ambos os reservatórios de água cinza estiverem no nível mínimo. Se apenas o reservatório superior estiver no nível mínimo, a bomba do reservatório inferior é acionada e o abastecimento daquele é feito com água cinza.
Para a localização do reservatório superior, adotou-se um segundo nível - acima dos reservatórios de água potável já existentes. A figura 3 ilustra a localização dos reservatórios inferior e superior.

Bomba de recalque

Para o dimensionamento da bomba de recalque, consideraram-se as prescrições contidas na NBR 5626/1998 (ABNT, 1998). Os parâmetros calculados e adotados foram: $Q=2,16$ $\mathrm{m}^{3} / \mathrm{h} ; \quad$ Hman $=25 \mathrm{mca} ; \quad \varnothing \mathrm{rec}=20 \mathrm{~mm}$. Dessa maneira, foi adotada a bomba MBA-XL 2cv considerando um recalque único, com tempo duração de aproximadamente $1 \mathrm{~h} 16 \mathrm{~min}$.

\section{Lavatórios e bebedouros}

O fornecimento de água potável para os lavatórios e bebedouros manteve-se conforme o projeto já existente, sendo necessária apenas a demolição das tubulações nos pontos de abastecimento das bacias sanitárias e torneiras de serviço. Optou-se por abastecer as torneiras de serviço com águas cinzas, pois o seu uso baseia-se no fornecimento de água para limpeza dos pisos da edificação. Ressalta-se a necessidade de sinalizar tais pontos com placas informando a não potabilidade da água. Para as águas residuais oriundas desses pontos, dimensionou-se um sistema de esgoto que recolhe $o$ efluente gerado e 0 transporta até 0 reservatório inferior, de onde posteriormente será bombeado até o reservatório superior. Não houve intervenção no sistema de esgoto existente para coletar os rejeitos dos vasos sanitários.

No interior do reservatório inferior, a água será tratada pelo processo de cloração utilizandose o clorador flutuante. Aliado a esse tratamento químico, será instalado um filtro na tubulação de recalque, a fim de garantir a retenção de partículas sólidas.

As figuras 4,5 e 6 ilustram a proposta de implantação do sistema de reúso para os lavatórios e bebedouros.

\section{Descargas sanitárias e torneiras de serviço}

O abastecimento das descargas sanitárias e torneiras de serviço será realizado por meio da tubulação proveniente do reservatório de águas cinzas. Para a definição da localização da prumada realizou-se previamente uma sobreposição das prumadas já existentes, tanto a 
de água fria quanto a de esgoto, a fim de evitar conflitos.

Para o efluente gerado pelos pontos em questão, manteve-se a instalação de esgoto já existente, sendo demolida apenas as partes que atendem os lavatórios e bebedouros. A figura 7 ilustra a proposta de implantação do sistema de reúso para os vasos sanitários e torneiras de serviço do $2^{\circ}$ pavimento.

\section{Estimativa de custos para implantação}

Conforme a proposta de sistema de reúso apresentada, o levantamento de custos contemplou os seguintes itens:

- Materiais para água fria: tubos de PVC soldável, joelhos PVC soldável, tês de redução e registros de gaveta, totalizando $\mathrm{R} \$ 1.834,65$.

- Materiais para esgoto: tubos de PVC série normal, joelhos PVC soldável, tês sanitários, reduções excêntricas, junções simples e caixas sifonadas $150 \times 150 \times 150 \mathrm{~mm}, \quad$ totalizando $\mathrm{R} \$ 2.655,59$.

- Materiais para o reservatório superior e

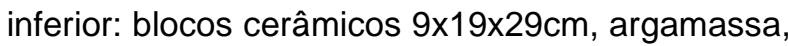
tinta, caixa d'água em poliestireno, tanque em poliestireno, filtro de água e bomba MBA-XL $2 \mathrm{cv}$, totalizando $\mathrm{R} \$ 4.476,20$.

- Materiais para reconstrução dos banheiros: chapas de gesso, argamassa colante, revestimento cerâmico, aluguel de caçambas, totalizando $\mathrm{R} \$ 3.788,88$.

- Mão de obra: pedreiro e auxiliar, bombeiro hidráulico e auxiliar e pintor, totalizando $\mathrm{R} \$ 13.626,56$.

Dessa forma, tem-se que o custo total de materiais para implantação do sistema proposto é de $\mathrm{R} \$ 12.755,32$. Acrescentando-se o custo da mão de obra, $\mathrm{R} \$ 13.626,56$, tem-se um investimento total de $\mathrm{R} \$ 26.381,88$.

Figura 3 - Detalhes dos reservatórios inferior e superior
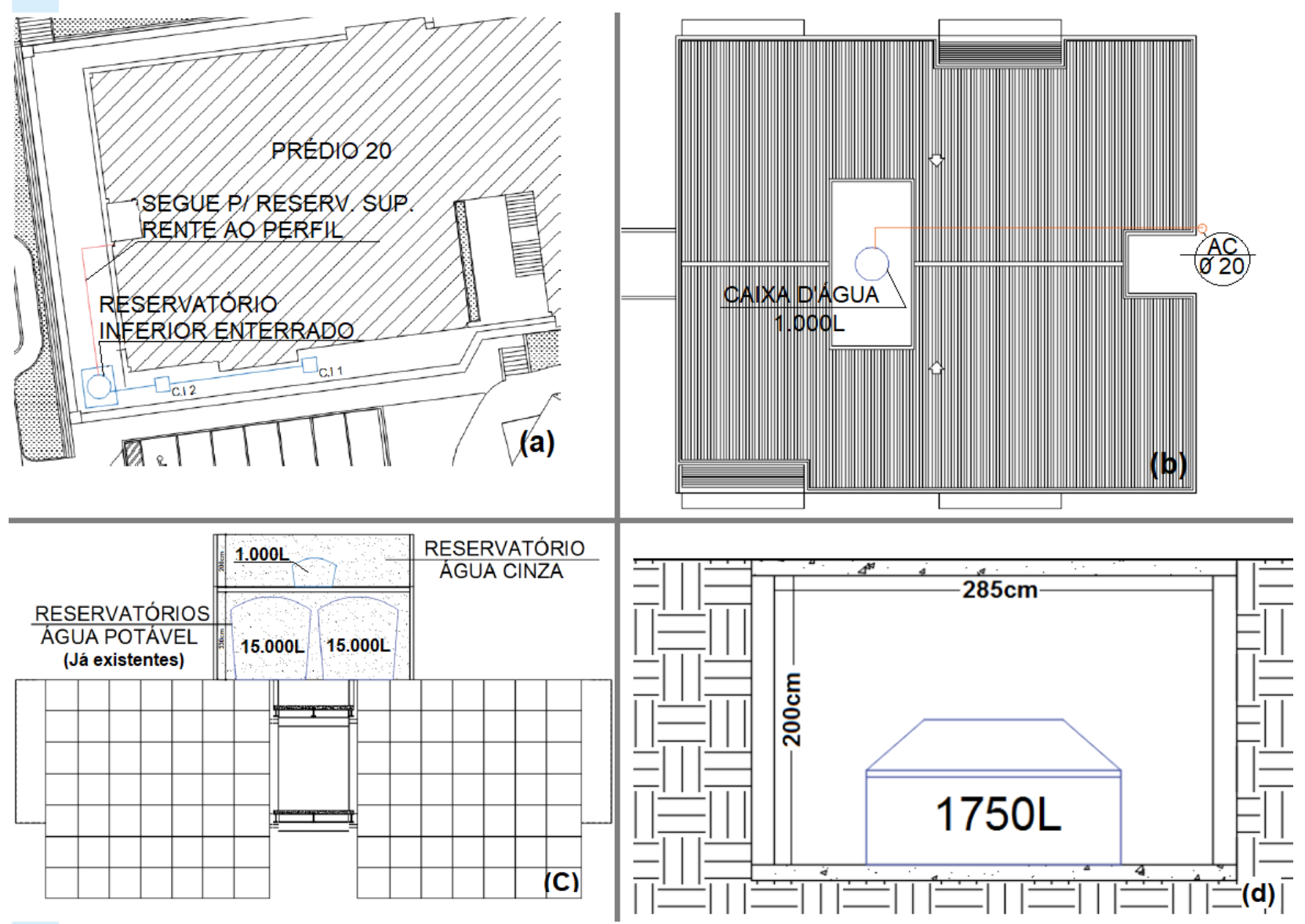

(a) Localização em planta do reservatório inferior enterrado. (b) Localização em planta do reservatório superior. (c) Vista lateral dos reservatórios de água potável e água cinza. (d) Corte do reservatório enterrado. 
Figura 4 - Proposta de implantação para lavatórios e bebedouros: 2 e 1ำ pavimentos

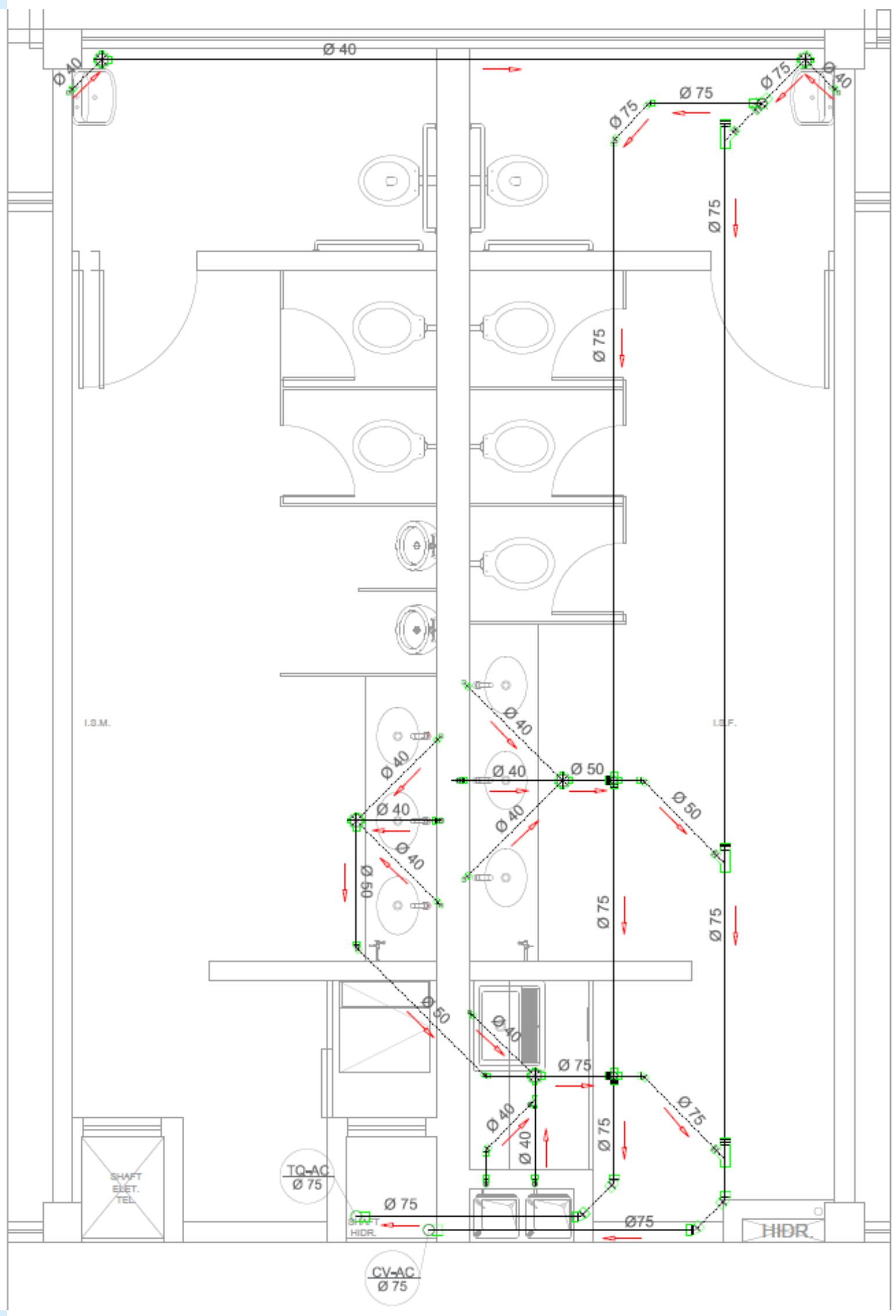


Figura 5 - Proposta de implantação para lavatórios e bebedouros: pavimento térreo

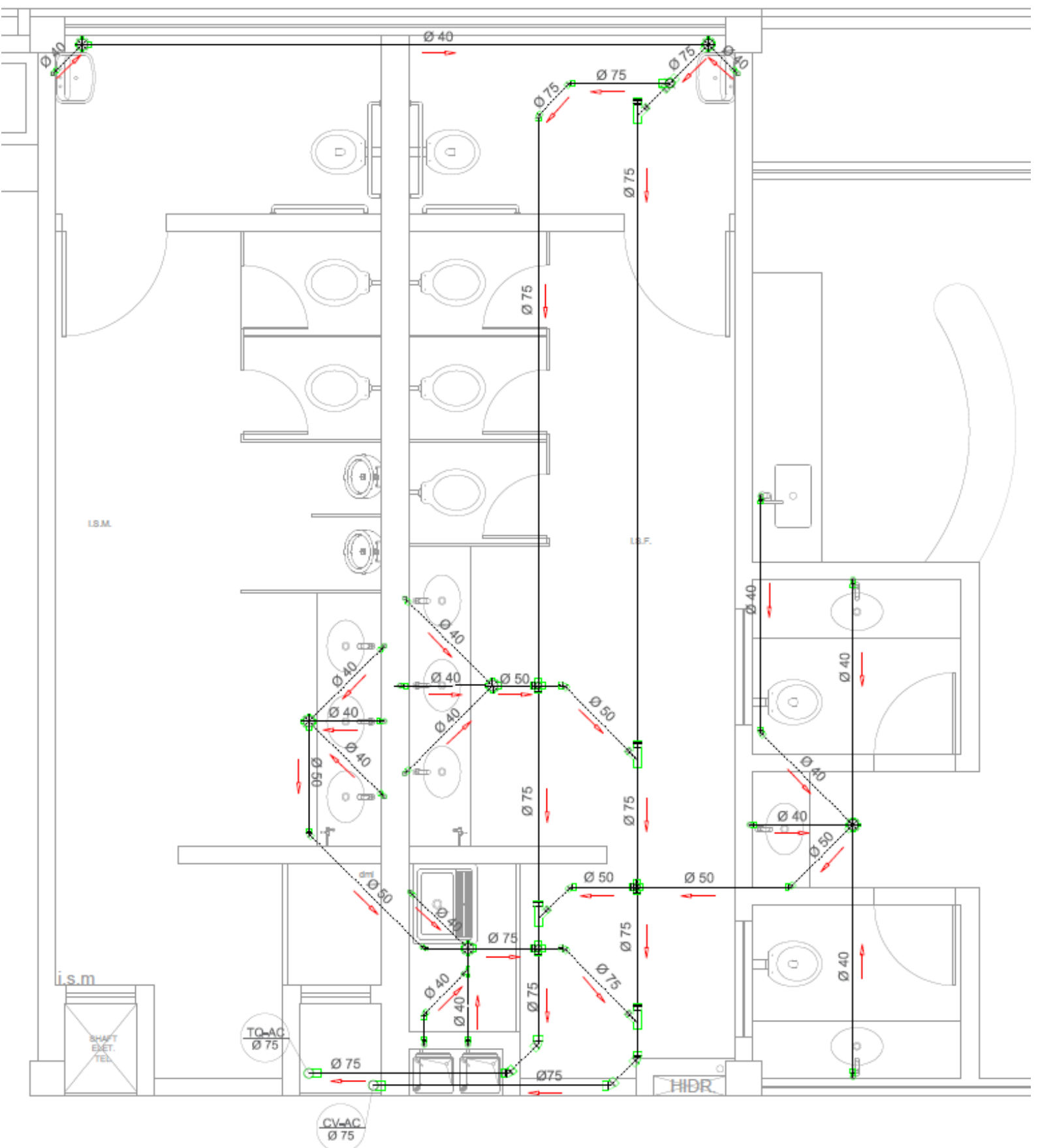


Figura 6 - Proposta de implantação para lavatórios e bebedouros: pavimento inferior

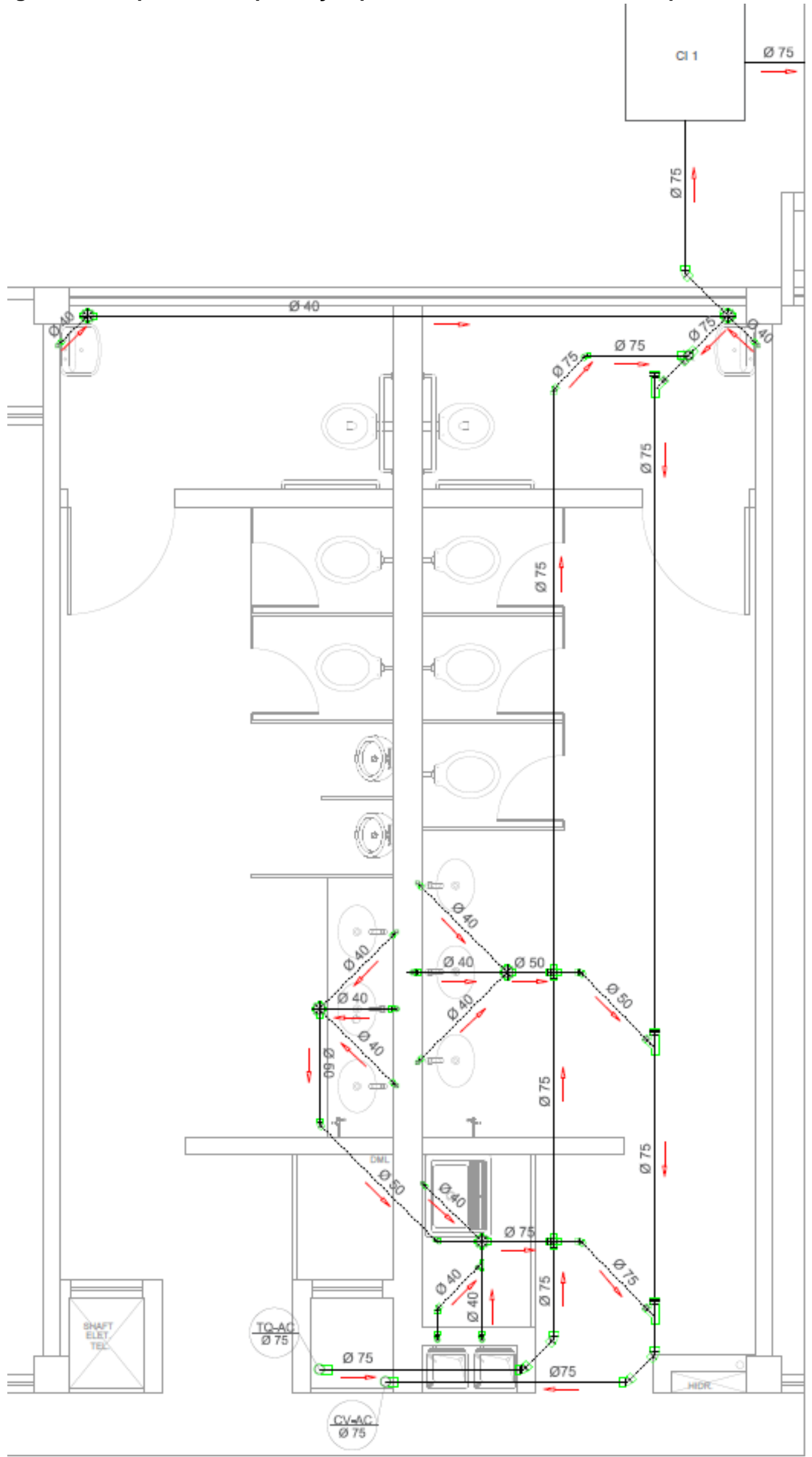


Figura 7 - Proposta de implantação para vasos sanitários e torneiras de serviço

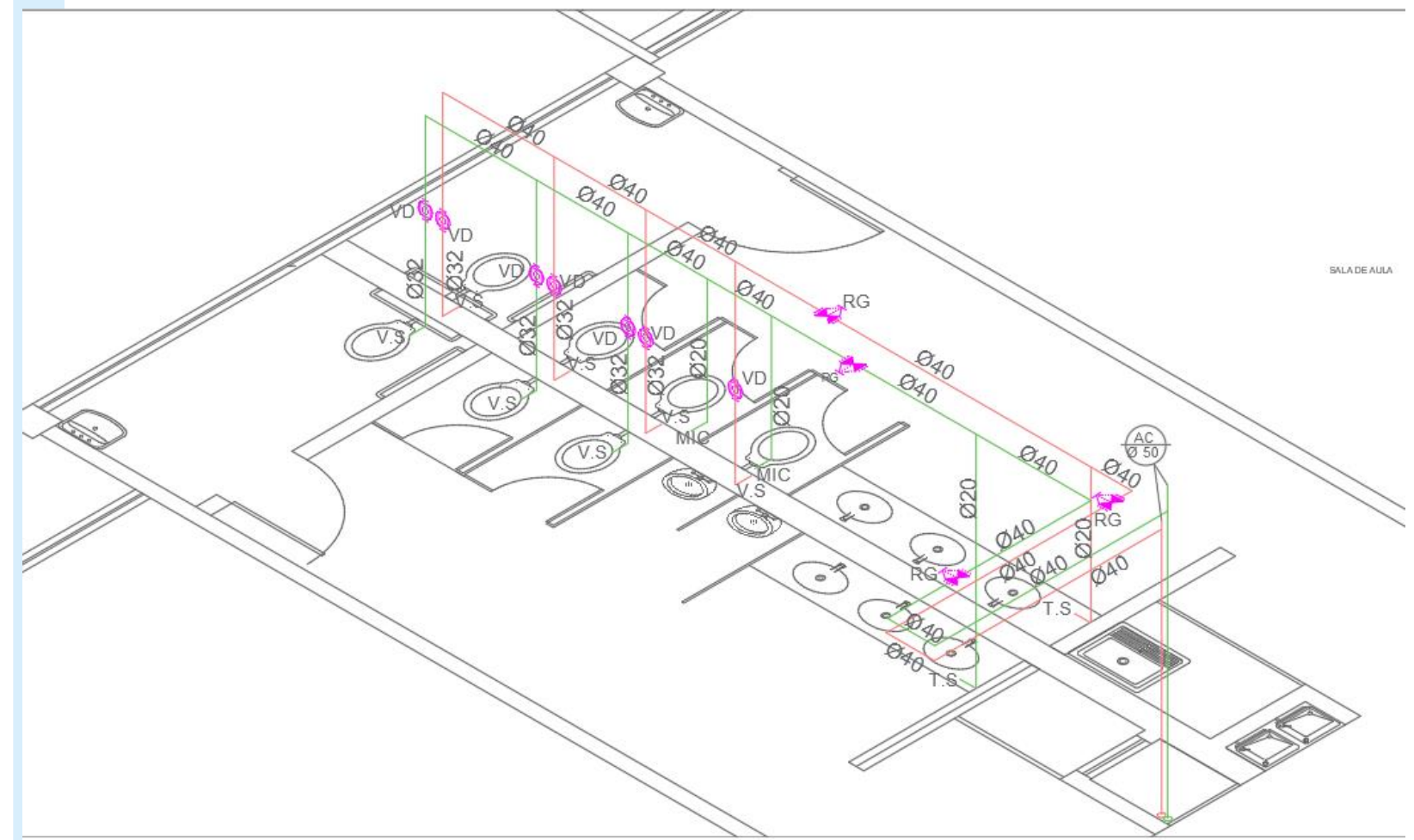

\section{Análise econômica}

Payback simples

O custo do investimento inicial refere-se ao valor de $\mathrm{R} \$ 26.381,88$ levantado. Para calcular a economia gerada pelo sistema, deve-se levantar a parcela referente ao consumo de água potável do prédio 20. Em média, 1.317.000 litros de água potável são consumidos mensalmente no campus 2 , acarretando um custo de $\mathrm{R} \$ 25.488,24$. O prédio 20 gera aproximadamente $43.150,40$ litros de água cinza mensalmente, 0 equivalente ao valor de $\mathrm{R} \$ 835,10$.

Dessa economia encontrada, é preciso descontar os gastos referentes ao consumo da energia elétrica pela bomba e com as pastilhas para o tratamento da água. No que diz respeito ao consumo de energia elétrica, tem-se que a bomba adotada de $2 \mathrm{cv}$ possui uma potência equivalente a $1472 W$. Considerando um único recalque no dia, de aproximadamente 1 hora e 16 minutos, funcionando 20 dias ao mês, obtém-se um gasto energético mensal de $37,38 \mathrm{kWh}$. Segundo os dados da Cemig, considerando-se tarifas na bandeira vermelha P1 (tarifa equivalente ao período de novembro/2019), cada kWh consumido custa $R \$ 0,62833$. Assim, o custo com energia elétrica da bomba de recalque é de $\mathrm{R} \$ 24,98$ mensais. Para o tratamento da água, será gasto um valor mensal médio de $\mathrm{R} \$ 101,37$ para a compra das pastilhas. Este valor foi obtido realizando-se uma média dos preços dos fornecedores. Portanto, o fluxo de caixa do período é de $R \$ 708,75$.

Calculando o payback simples utilizando-se da equação 1, encontra-se o seguinte resultado:

$$
\begin{gathered}
\text { Payback simples }=\left(\frac{R \$ 26.381,88}{R \$ 708,75}\right)=38 \text { meses } \\
=3 \text { anos e } 2 \text { meses }
\end{gathered}
$$

O resultado obtido informa que todo o investimento financeiro realizado será recuperado em um período de 38 meses. O payback isoladamente não informa se um investimento é viável ou não, por essa razão calculou-se também o VPL e a TIR.

VPL

Para calcular o VPL, as variáveis adotadas foram:

- Para o valor de $j$, adotou-se o período de 1 ano;

- Para o período n, adotou-se o período de 
vida útil do sistema. Segundo a NBR 15575:2013 (ABNT, 2013), para projetos hidrossanitários, esse período é de 20 anos;

- Para a TMA, adotou-se a taxa média de rendimento da poupança de $0,3153 \%$ ao mês, conforme dado obtido no Banco Central referente ao período-base de 01/10/2019 a 01/11/2019, o que equivale a um rendimento de $3,8487 \%$ ao ano;

- O investimento inicial é o valor de $\mathrm{R} \$ 26.381,88$ conforme levantado;

- Considerando-se que o período analisado é anual, para o fluxo de caixa será considerada a economia gerada pelo sistema em 1 ano, descontando-se a TMA, o que resulta em um fluxo de caixa anual de $R \$ 8.333,28$.

Aplicando-se a equação 2, tem-se:

$$
\begin{gathered}
V P L=\sum_{j=1}^{20} \frac{R \$ 8.333,28}{(1+0,038487)^{1}}-R \$ 26.381,88 \\
=R \$ 67.326,90
\end{gathered}
$$

O valor positivo encontrado para o VPL permite concluir que o projeto proposto é um investimento viável, conforme critério de análise discorrido no tópico 2.5. Sabendo-se que o VPL considera uma importante variável - o tempo -, pode-se inferir que um fator que contribuiu significativamente para este resultado positivo foi a baixa taxa de desconto adotada.

O VPL traz para o presente o valor futuro de todos os investimentos, descontando-se a TMA. Dessa forma, tem-se que o fluxo de caixa de entradas supera 0 fluxo de saídas em $\mathrm{R} \$ 67.326,90$; em outras palavras, ao final dos 20 anos, o projeto proporcionará a economia de $\mathrm{R} \$ 67.326,90$.

TIR

Para calcular a TIR, as variáveis adotadas foram: - Para o valor de $i$, adotou-se o período de 1 ano;

O investimento inicial é o valor de

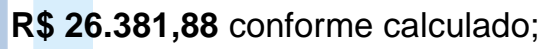

- $\mathrm{n}$ diz respeito ao período de 20 anos;

O fluxo de caixa no período é o valor calculado de $\mathbf{R} \mathbf{\$} \mathbf{8 . 3 3 3 , 2 8}$.

Aplicando-se a equação 3 , tem-se:

$\sum_{i=1}^{20} \frac{R \$ 8.333,28}{(1+T I R)^{1}}-R \$ 26.381,88=0 \quad T I R=26 \%$
A TIR calculada de $26 \%$, quando comparada com a TMA adotada, de $3,8487 \%$, confirma a viabilidade do projeto proposto. $O$ índice em questão refere-se à taxa de desconto que, quando aplicada ao fluxo de caixa, zera o VPL. No caso, como o período analisado é anual, isso significa que o projeto irá gerar um retorno de $26 \%$ ao final de sua vida útil, reforçando o quanto o sistema proposto é viável. Em outras palavras, o investimento realizado de $R \$ 26.381,88$ gera um retorno mensal de $\mathrm{R} \$ 708,75$ - o equivalente a quase $3 \%$ do valor investido. Esta taxa de retorno é superior à de muitos investimentos, como por exemplo a poupança, que apresenta um rendimento de $0,3152 \%$ ao mês.

\section{CONCLUSÕES}

É importante ressaltar que os fatores limitantes foram considerados nas conclusões desta pesquisa.

- Analisaram-se apenas as águas cinzas de um dos banheiros femininos do prédio 20 , o do pavimento térreo. Os valores obtidos nos monitoramentos foram extrapolados para os demais banheiros, femininos e masculinos, do referido prédio.

- Dentre os parâmetros contidos em normas e legislações, para esta pesquisa foram consideradas apenas as análises de $\mathrm{pH}$, condutividade elétrica e sólidos totais.

- As análises referem-se a um período de monitoramento específico - durante os meses de setembro/2019, outubro/2019 e novembro/2019 e não têm por objetivo apresentar um valor médio para o ano todo, mas sim servir como indicativo de ordem de grandeza dos parâmetros monitorados, de modo a se ter uma visão geral da qualidade da água cinza.

Assim sendo, as conclusões são as seguintes:

- Diante do contexto do tema abordado, reitera-se a importância da realização de estudos focando a valorização da água visando à diminuição do seu consumo, seja pela exploração de fontes alternativas ou por mecanismos que geram economia de água.

- Os monitoramentos realizados para o levantamento do volume de água cinza gerado apresentaram uma certa flutuação nos valores. Isso se deve ao fato de não existir um padrão constante no uso diário dos sanitários. Para a obtenção de um levantamento mais real, seria 
necessário o monitoramento durante períodos maiores e não apenas de cinco dias.

- Um ponto que vale ser destacado é com relação ao consumo de água potável no período de férias, durante os meses de janeiro e fevereiro, conforme a tabela 6 apresentada. Tem-se que o consumo foi, respectivamente, 580 e $762 \mathrm{~m}^{3}$. Os volumes citados, embora significativamente menores que aqueles dos demais meses, devem ser levados em conta. Tal fato evidencia que, mesmo com apenas uma parcela simbólica dos alunos na instituição, referente aos alunos da pós-graduação, há consumo de água, sobretudo com a limpeza e outras atividades comuns às escolas.

- As análises de qualidade mostraram que as águas cinzas do prédio 20 constituem-se uma fonte alternativa de reúso para fins não potáveis como descargas sanitárias, rega de jardins e lavagem de pisos. As amostras coletadas apresentam $\mathrm{pH}$ dentro da faixa recomendada, valores de condutividade elétrica próximos aos da água mineral e concentração de sólidos totais menor que a concentração recomendada para águas de reúso de classe 1 . Vale ressaltar que as águas cinzas coletadas, visualmente, apresentam um aspecto limpo se considerados os parâmetros de cor e turbidez.

Ao finalizar as análises quantitativas e econômicas, percebe-se que, apesar de o volume gerado ser suficiente para alimentar apenas 1/4 dos pavimentos e a economia gerada no prédio 20 (de $R \$ 708,75$ ) ser muito pequena, se comparada com a conta de água de todo o campus 2 ( $\mathrm{R} \$ 25.488,86)$, o projeto proposto ainda se mostra viável de acordo com o VPL e a TIR. O VPL mostrou que o investimento não é só viável, como também geraria um rendimento de $R \$ 67.326,90$ ao final da vida útil do sistema. Aliado ao VPL, ao se analisar a TIR, observa-se que ela apresentou um valor altamente superior à TMA, reafirmando a viabilidade do projeto. A vantagem de analisar a TIR é que esta se trata de uma ferramenta expressa em porcentagem ao invés de valores absolutos, facilitando a comparação com outros projetos e investimentos que possam surgir no campus 2 .

Para a realização de trabalhos futuros, sugere-se um estudo quantitativo, qualitativo e econômico para outros prédios do campus e até mesmo para outros campi a fim de se desenvolver um sistema de reúso de águas cinzas e se analisar a possibilidade do reúso também para a irrigação de áreas verdes.
Sugere-se também a elaboração de um projeto executivo para implantação do sistema de reúso de águas cinzas do prédio 20 , com levantamentos de custos mais detalhados.

\section{REFERÊNCIAS}

AMERICAN PUBLIC HEALTH ASSOCIATION. Standard Methods for the Examination of Water and Wastewater. 21 ed. Washington: ALPHA, 2005.

ASSOCIAÇÃO BRASILEIRA DE NORMAS TÉCNICAS. NBR 13969: Tanques sépticos: unidades de tratamento complementar e disposição final dos efluentes líquidos - projeto, construção e operação. Rio de Janeiro, 1997.

ASSOCIAÇÃO BRASILEIRA DE NORMAS TÉCNICAS NBR 5626: Instalação predial de água fria. Rio de Janeiro, 1998.

ASSOCIAÇÃO BRASILEIRA DE NORMAS TÉCNICAS NBR 8160: Sistemas prediais de esgoto sanitário Projeto e execução. Rio de Janeiro, 1999.

ASSOCIAÇÃO BRASILEIRA DE NORMAS TÉCNICAS. NBR 15575: Edificações habitacionais -

Desempenho. Rio de Janeiro, 2013.

BARROS, F. G. N.; AMIN, M. M. Água: um bem econômico de valor para o Brasil e o mundo. Revista Brasileira de Gestão e Desenvolvimento Regional, Taubaté, v. 4, n. 1, p. 75-108, 2007.

BRAGA, R. Fundamentos e técnicas de administração financeira. São Paulo: Atlas, 2011.

BRAGA, R. G.; JÚNIOR RIBEIRO, L. R. Avaliação técnica e econômica para o reúso de água cinza em uma instituição de ensino no município de Itajubá.

Revista Científica Universitas, Itajubá, v. 4, n. 1, p. 29-41, 2016.

BRITO, P. Análise e viabilidade de projetos de investimentos. 2. ed. São Paulo: Atlas, 2012.

BRIGHAM, E. F.; GAPENSKI, L. C.; ENRHARDT, M. C. Administração Financeira - Teoria e Prática. São Paulo: Atlas, 2001.

CHRISPIM, M. C. Avaliação de um sistema de tratamento de águas cinzas em edificação de campus universitário. 2014. 146 f. Dissertação (Mestrado em Saúde Ambiental) - Programa de Pósgraduação em Saúde Pública, Universidade de São Paulo, São Paulo, 2014.

CASAROTTO FILHO, N.; KOPITTKE, B. H. Análise de 
Investimentos: matemática financeira, engenharia econômica, tomada de decisão, estratégia empresarial. 11 ed. São Paulo: Atlas, 2010.

FUNDAÇÃO NACIONAL DA SAÚDE. Manual de Controle da Qualidade da Água para Técnicos que Trabalham em ETAS. Brasília, 2014.

GHISI, E.; MARINOSKI, A. K.; Aproveitamento de água pluvial para usos não potáveis em instituição de ensino: estudo de caso em Florianópolis, SC. Revista

Ambiente Construído, Porto Alegre, v. 8, n. 2, p. 6784, 2008.

LIMA, J. G. O paradoxo da água. Veja, São Paulo, ano 38, n. 41,12 out. 2005.

MAY, S. Caracterização, tratamento e reúso de águas cinzas e aproveitamento de águas pluviais em edificações. 2009. 200 f. Tese (Doutorado em Engenharia Hidráulica) - Escola Politécnica, Universidade de São Paulo, São Paulo, 2009.

MONTEIRO, R. C. de M. Viabilidade técnica do emprego de sistemas tipo "wetlands" para tratamento de água cinza visando o reúso não potável. 2009. 84 f. Dissertação (Mestrado em Engenharia Hidráulica) - Escola Politécnica, Universidade de São Paulo, São Paulo, 2009.

ORGANIZAÇÃO DAS NAÇÕES UNIDAS PARA EDUCAÇÃO, CIÊNCIA E CULTURA. Relatório Mundial das Nações Unidas sobre desenvolvimento dos recursos hídricos: Água para um mundo sustentável, 2015.

PAULA, H. M. de; FERNANDES, C. E. Otimização do tratamento de água cinza a partir do uso combinado de coagulantes químicos. Engenharia Sanitária e

Ambiental, [s.I.], v. 23, n. 5, p. 951-961, 22 out. 2018.

PAULA et al. Caracterização e tratamento de águas cinzas da construção civil - Estudo de caso: Edifícios da cidade de Goiânia - GO. Revista Eletrônica da Educação da Faculdade Araguaia, [s.I.], v. 13, n. 1, p. 127-138, 2018.

WESTON, J. F.; BRIGHAM, E. F. Fundamentos da Administração Financeira. 10 ed. São Paulo: Pearson Makron Books, 2004. 